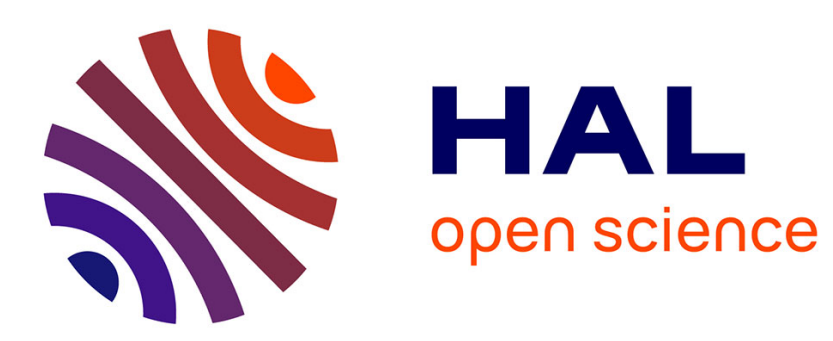

\title{
Strain field measurement on 3D surfaces: Application to petaloid base of PET bottles under pressure
}

\author{
Luc Chevalier, Yun Mei Luo, E. Monteiro
}

\section{To cite this version:}

Luc Chevalier, Yun Mei Luo, E. Monteiro. Strain field measurement on 3D surfaces: Application to petaloid base of PET bottles under pressure. 13th International ESAFORM Conference on Material Forming, Apr 2010, Italy. pp 1. hal-00777689

\section{HAL Id: hal-00777689 \\ https://hal.science/hal-00777689}

Submitted on 22 Jan 2013

HAL is a multi-disciplinary open access archive for the deposit and dissemination of scientific research documents, whether they are published or not. The documents may come from teaching and research institutions in France or abroad, or from public or private research centers.
L'archive ouverte pluridisciplinaire HAL, est destinée au dépôt et à la diffusion de documents scientifiques de niveau recherche, publiés ou non, émanant des établissements d'enseignement et de recherche français ou étrangers, des laboratoires publics ou privés. 


\title{
STRAIN FIELD MEASUREMENT ON 3D SURFACES: APPLICATION TO PETALOID BASE OF PET BOTTLES UNDER PRESSURE
}

\author{
Luc Chevalier*, Yun Mei Luo, Eric Monteiro \\ Université Paris-Est, Laboratoire MSME \\ 5 boulevard Descartes - Champs sur Marne \\ 77454, MARNE LA VALLEE Cedex 2, FRANCE
}

\begin{abstract}
The main goal of this paper is to provide an identification tool for the orthotropic elastic properties in the 3D regions of PET bottles. We focus on the behavior of the petaloid bases when bottles are submitted to an internal pressure. A stereo correlation software has been developed to evaluate the membrane strains. Two bases named VS (small valley) and VL (large valley), which highlight different behavior at the ESC (environmental stress cracking) test, are compared with this tool. Coupled with a finite element simulation managed on the same bases, these results allow the identification of the induced mechanical properties.
\end{abstract}

KEY WORDS: Stereo correlation, strain field measurement, polyethylene terephthalate bottles, petaloid base, identification by coupled experimental-calculation

\section{INTRODUCTION}

The mechanical properties of stretch blow-molded PET bottles are largely dependent of the strain history during the process [1]. Because the biaxial elongation of macromolecules induces large modifications of the material mechanical properties, it is difficult to manage an accurate simulation: properties are not well known in the base region of the bottles.

We present an identification procedure of the modulus distribution in the petaloid base. It involves an experimental aspect where a stereo correlation technique [2] is developed to build the strain field on the 3D surface of the petaloid base. These experimental results are compared with finite element simulations managed on the same base. The comparison leads to the distribution of the elastic properties over this surface. Developments are illustrated on two different designs of petaloid bases (see Figure 1), one with large valleys (VL) between the five feet and one with small valleys (VS) which exhibit very different performances during the ESC test [3]. The VL base resists much better than the VS one.

\section{EXPERIMENTAL MEASUREMENT}

The stereo correlation technique is based on the determination of the apparent displacement between two digital images of the same object taken by two cameras. We used the Correli software extended to large strain for polymer studies. This software has already been implemented in Matlab ${ }^{\mathrm{TM}}$ [4].

Since the distance between cameras is small $(200 \mathrm{~mm})$ compared with the distance between the cameras and the objects (about $2 \mathrm{~m}$ ), the geometrical problem of the correspondence is reduced to a simple linear expression that defines the coordinate $z$ : the 3D surface is then described as a function $z=$ $\mathrm{f}(x, y)$ and we can compute the displacement which are also functions of coordinates $x$ and $y$.

This technique can be applied to the case of petaloid bases: first when the PET bottle is empty and not loaded, second when the same bottle is submitted to a 5 bar internal pressure. Figure 1 visualizes the initial surface and the displacement field from the initial and deformed surface under a 5 bar internal pressure, for the two bases.

The left shape is the VS shape where one can see the effect of the internal pressure: injection point and feet move quasi homogeneously in the $\mathrm{Z}$ direction which is representative of a global expansion of the bottle due to the pressure. The right shape is the VL shape: feet move in the $\mathrm{Z}$ direction while the injection point remains still. The base design leads to a bending phenomenon where each foot rotates 
around the injection point. Both bases react differently to the load and that may be put in relation with the better resistance of VL bases in the ESC test.
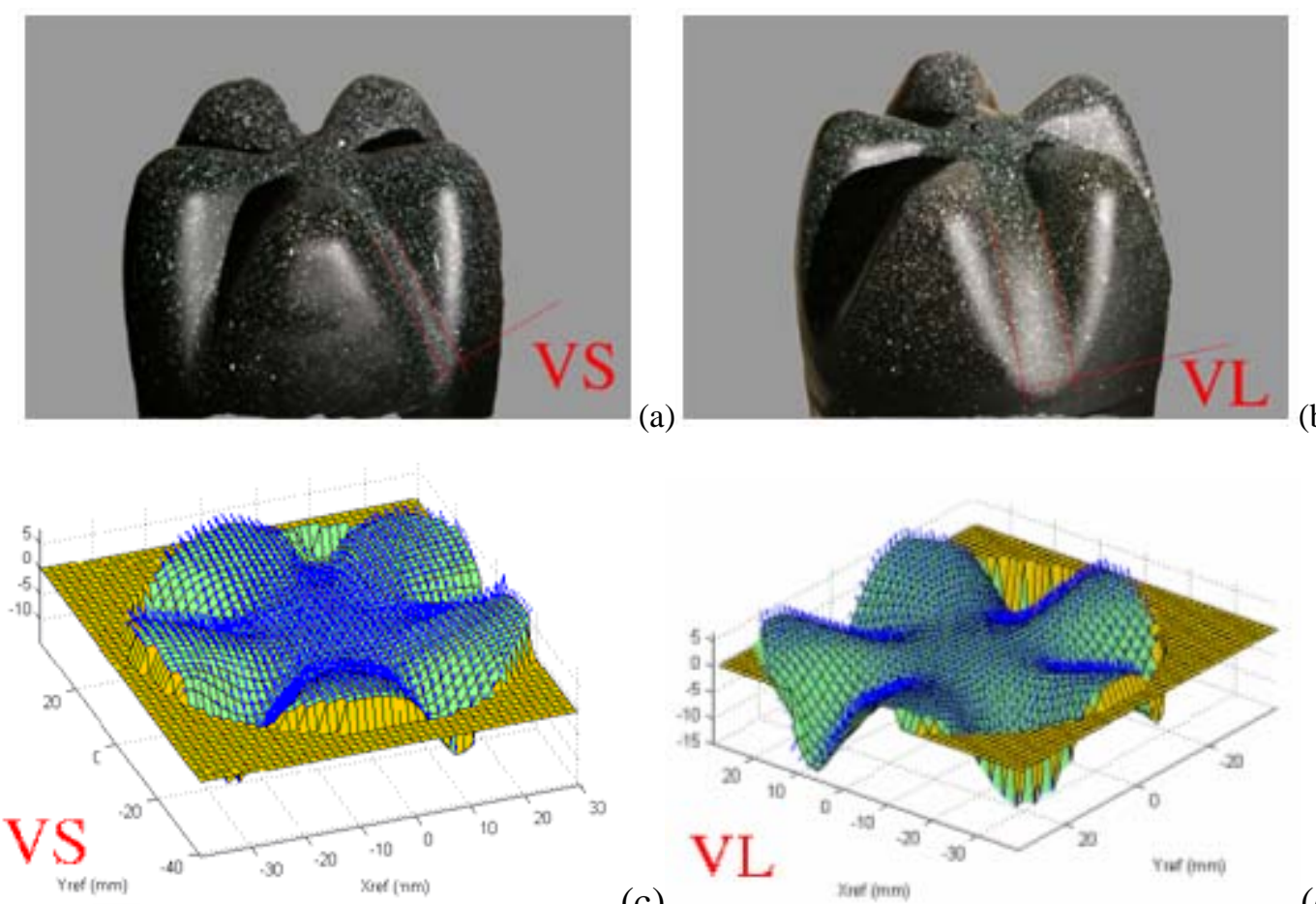

(C)

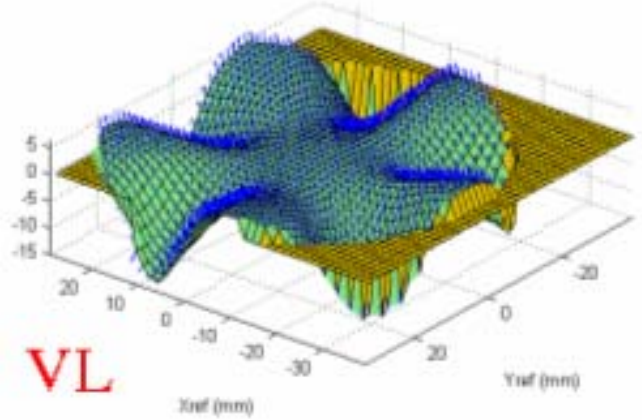

(d)

Figure 1: 2L soda bottle petaloid bases: (a) small valley (VS), (b) large valley (VL).

Bottle bases construction in a circular zone around the injection point (PI) and visualization of the displacement field when bottles are under internal pressure: (c) VS base, (d) VL base.

One can compute the membrane strains by applying to the 3D strain tensor, the projection tensor in the tangent plane of the 3D surface at the considered point. If we focus on the injection gate, the behavior of the VS base is quasi equibiaxial and linear from 0 to 5 bar of internal pressure. For VL base the behavior is clearly not linear and this, even for very low level of pressure: permanent strains cannot be the explanation, so a bending effect should be not neglected. The geometry of the feet leads to a first bending effect where feet come together towards the axis of the bottle. This leads to a compression on the outside skin of the bottle surface. Then, when pressure increases, the inflation of the bottle has an opposite effect and strain becomes positive. Consequently, for the same pressure (5 bar), the strain level is about six times lower for VL than for VS. This is an important difference of behavior that explains the better resistance of the VL base to ESC test.

\section{NUMERICAL- EXPERIMENTAL COMPARISON}

The numerical simulation of the change of the bottle shape under internal pressure is managed using Patran-Nastran finite element software. The CAD models of the bottle and petaloid bases have been meshed with linear shell elements. In the case of the whole bottle, about 48560 nodes have been used to make sure of the accuracy of the numerical solution. The boundary conditions are applied on the top circle of the bottleneck: $u_{r}=u_{\theta}=u_{z}=0$ and the node at the injection gate: $u_{r}=u_{\theta}=0$.

We suppose that the stress distribution is not affected by the elastic properties of the material. An isotropic and homogeneous elastic law $(E=1200 \mathrm{MPa}$ and $v=0.38$ ) has been used for these calculations. After measurement and modeling of the thickness evolution on the bottle, the finite element simulation is managed for an internal pressure of 5bar. The principal stresses $\sigma_{1}$ (the major one) and $\sigma_{2}$ are represented on Figure 2, both are in tension on the outside skin of the surface. 

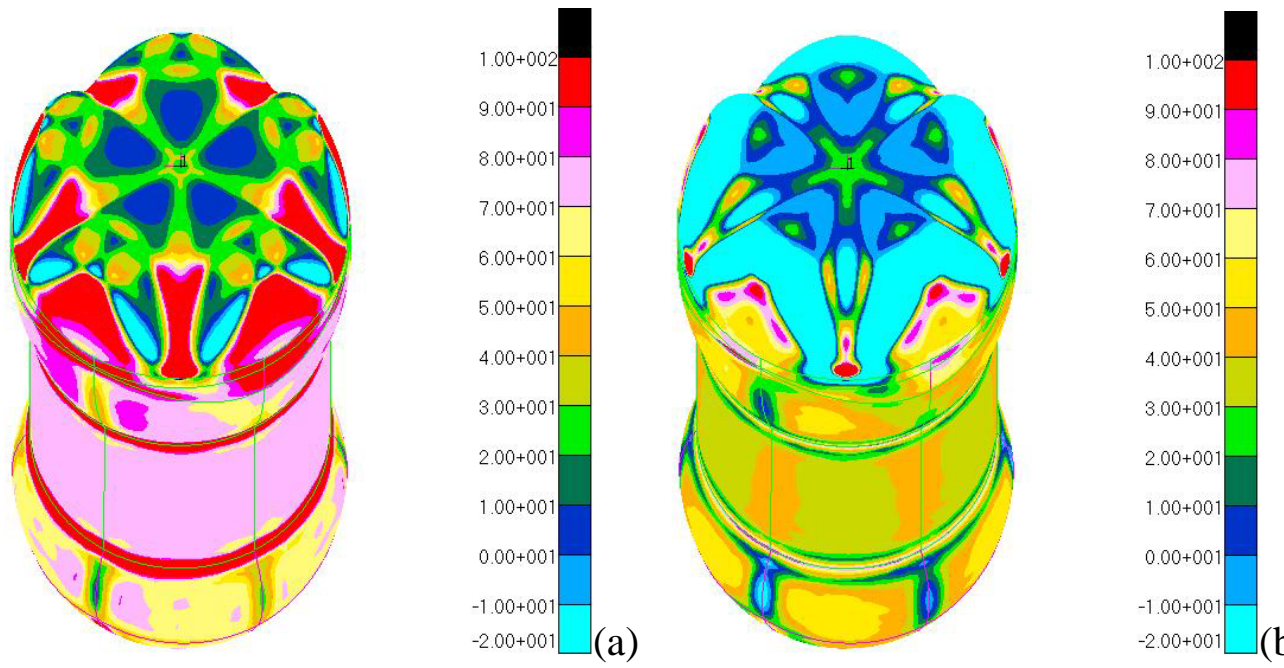

Figure 2: Finite element simulation on VS for an internal pressure of 5 bar. (a) the major principal stress $\sigma_{1}$; (b) the minor principal stress $\sigma_{2}$ on the $3 D$ outside surface of the petaloid base.

We focus on the results near the injection gate (see Figure 3). The evolution of the principal stresses on the inside and outside surfaces is plotted and one can see that the stress state is purely biaxial at this point. For the VS base (Figure 3a) one can also notice the linearity of the behavior. On Figure 3b, one can see that the behavior of the VL base is non linear and clearly different from VS. Because of the non linear behavior of the VL base, the outside stress is lower in VL than in VS under 5bar pressure. This may help to explain the better resistance of this base to ESC test.

(a)
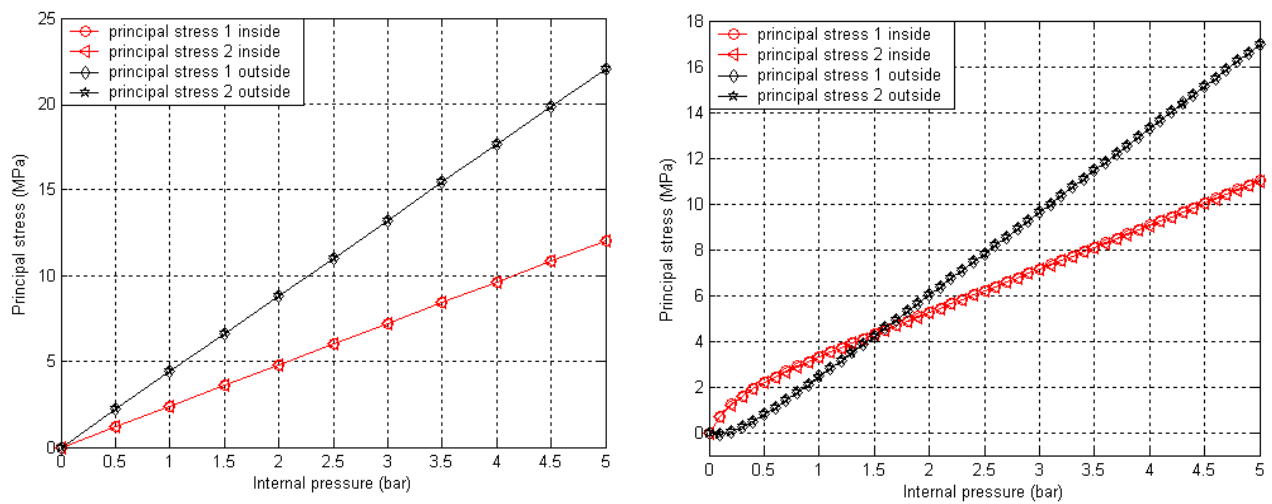

(b)

Figure 3: Principal stresses at the injection gate for VS (a) and VL (b) bases.

\section{RESULTS}

On one hand, we consider the stereo correlation measures of both principal strains $\varepsilon_{1}$ and $\varepsilon_{2}$ related to principal directions. On the other hand, using an isotropic and homogeneous elastic finite element calculation, we have estimated both principal stresses $\sigma_{1}$ and $\sigma_{2}$. Assuming that the principal directions are overlapping with the orthotropic directions, we can identify the orthotropic elastic properties: four parameters $\left(E_{1}, E_{2}, v_{12}\right.$ and $\left.v_{21}\right)$ are to be found from the following system.

$$
\begin{aligned}
& \varepsilon_{1}=\frac{\sigma_{1}}{E_{1}}-\frac{v_{21} \sigma_{2}}{E_{2}} \\
& \varepsilon_{2}=\frac{\sigma_{2}}{E_{2}}-\frac{v_{12} \sigma_{1}}{E_{1}}
\end{aligned} \quad \text { with: } \frac{v_{12}}{E_{1}}=\frac{v_{21}}{E_{2}}
$$


In the case the modulus $E_{1}$ is greater than $E_{2}$, physical argumentation suggest that $v_{12}$ should be greater than $v_{21}$. We set $v_{12}$ to $v_{0}$ in our identification procedure and consequently none of Poisson ratios can exceed 0.5 . It is the easy to compute $E_{1}$ and $E_{2}$ :
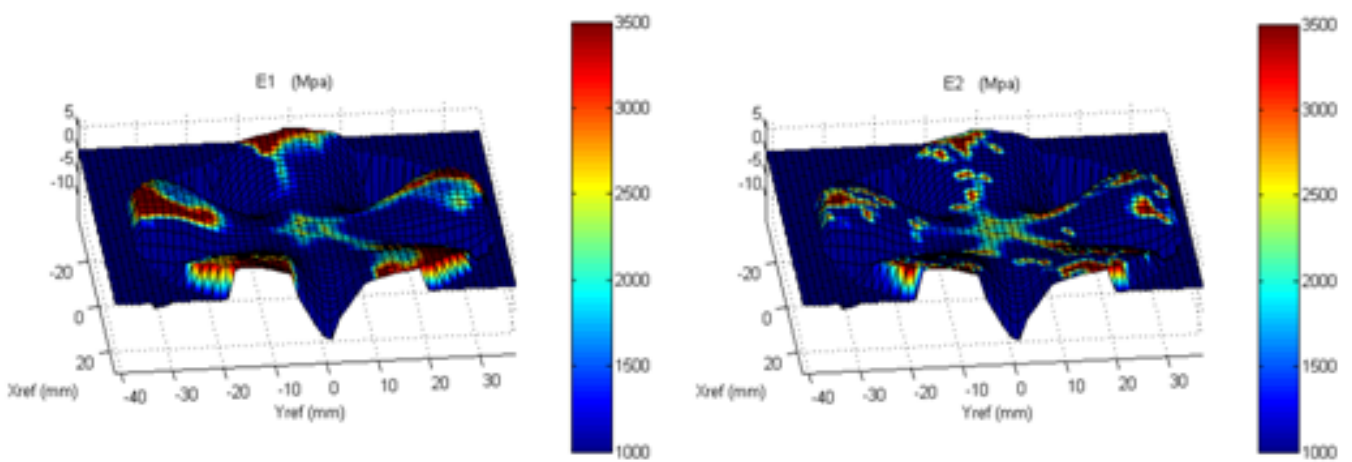

Figure 4: Identification of Young's modulus for anisotropic materials, distributions of modulus $E_{1}$ and $E_{2}$ for the VS petaloid base.

One can see on Figure 4 that the modulus $E_{1}$ increases when we follow the radial direction towards the feet but not in the valley where the modulus remains low. One can also notice that the distribution of $E_{2}$ is not similar to the distribution of $E_{1}$, especially on the feet, which means that the material had become anisotropic during the process. The region near the injection gate is not re-enforced and both modulus $E_{1}$ and $E_{2}$ are equal to the amorphous PET value.

For the VL base, the identification procedure of the Young modulus will be more complex because it must take into account the complete history of the base loading that is non linear.

\section{CONCLUSION}

The PET material of the petaloid bases is clearly heterogeneous and slightly anisotropic when far from the injection gate

For the VL base, according to the non linear effect, it is necessary to reproduce similar evolution of stress and strain versus internal pressure. The non linear behaviour of the VL base explains the better resistance of this base to ESC test. On the other hand, the identification procedure of the Young modulus will be more complex because it must consider the complete history of the base loading.

\section{REFERENCE}

[1] Chevalier, L., Linhone, C., Regnier, G.: Induced crystallinity during stretch-blow moulding process and its influence on mechanical strength of poly(ethylene terephthalate) bottles. Plastics rubber and composites 28, 8, 393-401, 1999.

[2] Garcia, D., Orteu, J.-J., Penazzi, L.: A Combined Temporal Tracking and Stereo-correlation Technique for Accurate Measurement of 3D Displacements : Application to Sheet Metal Forming, Journal of Materials Processing Technology, 125-126, pages 736-742, 2002.

[3] Li X.Y.: Environmental Stress Cracking Resistance of a New Copolymer of Bisphenol-A. Polymer Degradation and Stability, 90 (1), 44-52, 2005.

[4] Chevalier,L., Calloch, S., Hild, F., Marco, Y.: Digital image correlation used to analyze the multiaxial behavior of rubber-like materials. European Journal of Mechanics - A/Solids, Volume 20, Issue 2, pages 169-187, 2001. 